\title{
Acute Severe Hypertension in Children: An Ongoing Search for Therapeutic Agent of Choice
}

\author{
Nitin Dhochak ${ }^{1} \cdot$ Rakesh Lodha $^{1}$
}

Received: 5 November 2021 / Accepted: 15 November 2021 / Published online: 25 November 2021

(c) Dr. K C Chaudhuri Foundation 2021

Children with acute severe hypertension present to pediatric emergency with end-organ dysfunction (hypertensive emergency); this demands prompt therapy. The blood pressure cutoffs for acute severe hypertension are not very clear and vary among guidelines: (a) $30 \mathrm{~mm} \mathrm{Hg}$ or more above the 95th centile (2017 American Academy of Pediatrics guidelines); (b) $20 \%$ above the stage 2 hypertension limit (2016 European Society of Hypertension guidelines) [1, 2]. Both guidelines also mention that these are commonly used cutoffs but children may have features of end-organ dysfunction even at lower blood pressures, if the blood pressure rise is abrupt.

There is lack of evidence-based recommendations regarding the choice of therapy. Intravenous (IV) continuous infusion is recommended over bolus therapy or oral therapy in children with hypertensive emergency for graded blood pressure reduction and avoiding precipitous blood pressure falls. These recommendations are based on observational studies and expert opinions, rather than clinical trials.

Options for IV infusion therapy include sodium nitroprusside, labetalol, esmolol, diuretics (furosemide), hydralazine, nicardipine, and urapidil [1, 2]. Sodium nitroprusside has traditionally been the favored drug due to its rapid action (within seconds) and short half-life ( $2 \mathrm{~min})$, hence ease of titration. There are concerns of cyanide toxicity with prolonged infusions (beyond $48 \mathrm{~h}$ ) especially in children with renal failure.

Lad et al. have described a retrospective review of drug therapies in hypertensive crisis (both hypertensive emergency and urgency) in children [3]. The drugs utilized were sodium nitroprusside, nitroglycerin, and labetalol. They found that children receiving labetalol [as first-line or addon or transition from other IV antihypertensive infusions

Rakesh Lodha

rakesh_lodha@hotmail.com

1 Department of Pediatrics, All India Institute of Medical Sciences, New Delhi 110029, India (sodium nitroprusside, nitroglycerin) in the first $24 \mathrm{~h}$ of management] had significantly higher achievement of 95th centile blood pressure at 12-24 h compared to sodium nitroprusside/nitroglycerin group. Neurological recovery was also higher in labetalol group. Incidence of hypotension was similar in both groups. The results were similar when they compared children receiving labetalol alone vs. non-labetalol group; however, it is not clear if the baseline characteristics matched. It would have been useful to provide the doses of the drugs used. The authors have not mentioned the numbers of children receiving sodium nitroprusside and nitroglycerin in the non-labetalol group. Nitroglycerin, being predominantly a venous vasodilator, may have lower efficacy than sodium nitroprusside and more likely to cause hypotension in fluid depleted patients.

Acute severe hypertensive crisis in children usually have some identifiable underlying cause, which may impact the choice of therapy. In children with fluid overload and acute kidney injury, furosemide is the preferred therapy. Esmolol has been found more effective than sodium nitroprusside in patients with coarctation of aorta [4]. Nicardipine is preferred in patients with intracranial bleed. Labetalol is avoided in children with underlying asthma, acute left ventricular failure, and bradycardia. Cyanide toxicity (lactic acidosis, decreased oxygen saturation, bradycardia, convulsions, etc.) should be carefully looked for in children with acute kidney injury on sodium nitroprusside infusion [5].

As of now, there is no evidence-based recommendation for the drug of choice for acute severe hypertension in children. Underlying etiology and comorbidities should be considered while prescribing the antihypertensive agents. The current study demonstrated good efficacy with labetalol without significant adverse effects. Clinical trials are needed for better determination of comparative efficacy among different antihypertensive agents, but low prevalence of the condition is a major impediment. Costs should also be studied, as labetalol is relatively more expensive than the other drugs. 


\section{Declarations}

Conflict of Interest None.

\section{References}

1. Flynn JT, Kaelber DC, Baker-Smith CM, Blowey D, et al. Clinical practice guideline for screening and management of high blood pressure in children and adolescents. Pediatrics. 2017;140:e20171904.

2. Lurbe E, Agabiti-Rosei E, Cruickshank JK, et al. European Society of Hypertension guidelines for the management of high blood pressure in children and adolescents. J Hypertens. 2016;34:1887-920.
3. Lad S, Patil M, Jayashree M, et al. Efficacy and safety of intravenous labetalol in acute hypertensive crisis in children. Indian J Pediatr. 2021. https://doi.org/10.1007/s12098-021-03707-7.

4. Tabbutt S, Nicolson SC, Adamson PC, et al. The safety, efficacy, and pharmacokinetics of esmolol for blood pressure control immediately after repair of coarctation of the aorta in infants and children: a multicenter, double-blind, randomized trial. J Thorac Cardiovasc Surg. 2008;136:321-8.

5. Hari P, Sinha A. Hypertensive emergencies in children. Indian $\mathbf{J}$ Pediatr. 2011;78:569-75.

Publisher's Note Springer Nature remains neutral with regard to jurisdictional claims in published maps and institutional affiliations. 